\title{
Mind the gap: turbulent combustion model validation and future needs
}

\author{
Simone Hochgreb
}

Department of Engineering, University of Cambridge, Trumpington St, Cambridge, CB2 1PZ, United Kingdom

\begin{abstract}
This overview collects a range of well characterized experiments used in the step-wise validation of turbulent combustion models, from gas phase non-premixed jet flames to spray flames, and from simple symmetric jets to real device geometries, focusing primarily on statistically steady state experiments. We discuss how the experiments and models are constructed, approaches to modelling, and the tradeoffs between the level of detail and computational demands. The review highlights a number of experiments used for benchmarking models, selecting a few examples where models have clearly succeeded, as well as some areas where there are clear needs in the experimental database. In particular, the areas of turbulent spray combustion and soot prediction, as well as combustion under high pressures appear as the least developed and present the clearest gaps for both models and experiments. Based on the successful application of advanced methods of uncertainty quantification to a number of problems in reacting flows, we suggest that these methods might be used to advantage in the design of experiments. This would enable an upfront examination of the extent to which comparisons between measurable scalars and velocities allow clear distinction between model features.
\end{abstract}

Keywords: turbulent combustion, diagnostics, model validation

Email address: simone.hochgreb@eng. cam.ac.uk (Simone Hochgreb) 


\section{Introduction}

The general objective in the design of devices using turbulent combustion is to produce clean hot gases in a stable manner over a wide range of conditions, either for the direct, efficient conversion into mechanical power in engines and turbines, or for the indirect use of enthalpy for heat exchange with some other fluid, for purposes of heating or power generation. This apparently simple mission stumbles into inherent tradeoffs between stability and the production of undesirable pollutant byproducts. Enormous progress has been made in numerical modelling of reacting and non-reacting flows, yet one cannot always make accurate predictions about the pollutant emissions, instability or reaction limits of new devices without building them. This state of affairs results from the incomplete knowledge of some of the fundamental kinetics (particularly in the case of large hydrocarbons and soot), as well as from inherent difficulties in predicting the behavior of highly non-linear turbulent flow systems.

In this paper, we take a very broad view of the state of turbulent model validation over the past decade, and set the stage for a discussion of what may be opportunities for developing more efficient validation strategies for turbulent combustion models. There is only so much room in a topical review (and panel discussion) to cover such a broad topic. The present paper provides an entry point by collecting information on validation targets and methods, and identifies some of the directions for research and methods. For conciseness, we only consider stabilized flames as a target, excluding the growing database of unsteady experiments in combustion vessels, rapid compression machines, and engines.

The paper is structured as follows: a brief review of the issues in turbulent combustion is presented, describing the key difficulties in modelling and measurements, followed by a discussion of the process of validation, existing databases, and the state of the art in model comparisons. The review leads to a reflection on the gaps in the database, and finally, to questions about how current models can be used to improve the development of validation experiments.

\section{Turbulent Combustion Models and Closures}

\section{2.1. Multiscales and Multiscalars}

There are three main challenges associated with modelling turbulent reacting flows, as discussed in many distinguished reviews and books [1--4]: (a) the vast range of temporal and spatial scales, from device spatial scales of the order of meters down to micrometer scales where mixing and viscous dissipation take place; (b) the range of species reacting at different time scales; (c) the highly non-linear behavior of chemical reactions with the highly variable local temperature. For the modeller, this means that not all scales and not all species may be accurately reproduced, and a compromise between fidelity and computational resources must be made. For the experimentalist, these demands challenge the dynamic range and resolution capability of any technique. The mesh resolution in practical CFD calculations cannot span the range of scales, and some spatial averaging or filtering must be done: subgrid models must therefore account for the non-linear contributions of the unresolved fluctuations.

The ratio of the largest length scale $\ell_{T}$ to the molecular diffusion length scale $\ell_{K}$ can be approximated based on the hypothesis of scale-invariant dissipation rate [5, 6], $\left(\frac{\ell_{T}}{\ell_{K}}\right)=\operatorname{Re}^{\frac{3}{4}}=\left(\frac{u_{T} \ell_{T}}{v}\right)^{\frac{3}{4}}$, where $u_{T}$ is the integral turbulent velocity, $v$ the fluid viscosity, and Re the corresponding turbulent Reynolds number. Correspondingly, integral time scales vary according to $\left(\frac{\tau_{T}}{\tau_{K}}\right)=\operatorname{Re}^{\frac{1}{2}}$. At the high pressures and flows rates associated with high specific power in gas turbines and engines, Re can be of order $10^{3}$ to $10^{5}$, so that two to three orders of magnitude in time or space need to be resolved. Whilst this lies in the realm of petascale direct numerical simulations, it is clearly beyond the reach of repeated design calculations. The turbulent time scales are compared to the corresponding chemical (and chemical-diffusive) scales $\tau_{c}$, generating the Damköhler number, $\mathrm{Da}=\tau_{T} / \tau_{c}$ and Karlovitz number, $\mathrm{Ka}=\tau_{\mathrm{c}} / \tau_{\mathrm{K}}[7,8]$, and the two numbers are related by $\mathrm{Da} \mathrm{Ka}=\tau_{T} / \tau_{K}=\mathrm{Re}^{1 / 2}$.

Flame-like structures are associated with short chemical time scales, with $\mathrm{Da}$ in the hundreds, and these tend to exist as wrinkled or intermittently extinguished flames up to Ka of the order of thousands [9, 10]. Under autoignition processes taking place at the initiation of combustion in compression-ignition engines, time scales can be large, with low Da, and reactions take place in a more spatially distributed mode. High power density demands higher Re and Ka numbers, and the job of the designer becomes to understand the limits of turbulent mixing and reactions for a particular objective.

The focus of a large number of experimental and modelling studies has been to investigate how well models of turbulent diffusion and premixed flames are able to represent the observed species or flame propagation characteristics, and to some extent the limits of stable combustion under these conditions. These studies, and the philosophy governing the experimental efforts de- 


\subsection{Governing equations}

Turbulent combustion models use differential conservation equations, typically in an Eulerian framework, to make predictions about the evolution of the relevant scalars and velocity fields. At the simplest level, what makes combustion special in comparison to nonreacting turbulent flows is the evolution of the scalar species and release of thermal energy, which leads to density changes, and thereby a coupling with momentum. In practice, the key scalars are species which represent progress of reaction or heat release (often a sum of $\mathrm{CO}, \mathrm{CO}_{2}$, and $\mathrm{H}_{2} \mathrm{O}$ ), temperature, and a total mixture fraction $Z$, usually a normalised linear combination of species representing the total original atomic abundance in the reacting streams. If we consider only gas phase species, in the low Mach number limit for many situations, the conservation equation for a scalar $\psi$ reads, in the approximation of Fickian diffusion:

$$
\frac{\mathrm{D} \rho \psi}{\mathrm{D} t}=\frac{\partial \rho \psi}{\partial t}+\nabla \cdot(\rho \mathbf{u} \psi)=\nabla \cdot\left(\rho D_{\psi} \nabla \psi\right)+\dot{\omega}_{\psi}
$$

where radiative heat losses are not considered in the case of the energy equation. Equation 1 can be filtered or time-averaged [2, 3, 11] to yield an equation of form:

$$
\frac{\partial \bar{\rho} \tilde{\psi}}{\partial t}+\nabla \cdot(\bar{\rho} \tilde{\mathbf{u}} \tilde{\psi})=\nabla \cdot \mathbf{T}_{\psi}^{\mathbf{u}}-\nabla \cdot \mathbf{T}_{\psi}^{\mathbf{D}}+\overline{\dot{\omega}}_{\psi}
$$

where the flux terms for convection with velocity $\mathbf{u} 155$ and density $\rho, \mathbf{T}_{\psi}^{\mathbf{u}}=\bar{\rho}(\tilde{\mathbf{u}} \tilde{\psi}-\overline{\mathbf{u} \psi})$, molecular diffusion, 156 $\mathbf{T}_{\psi}^{D}=\overline{\rho D_{\psi} \nabla \psi}$ and reaction $\overline{\dot{\omega}}_{\psi}$ require modelling. The ${ }^{157}$ averaged or filtered terms do not in general correspond 158 to the values of the operators evaluated at averaged 159 or filtered conditions: departures from the averaged 160 temperature create significant deviations in the reaction ${ }^{161}$ rates of most scalars, which depend exponentially on the ${ }^{162}$ local temperature. Extensions and variations of these ${ }^{163}$ models are required, for example, for systems involv- ${ }^{164}$ ing multiple phases, such as spray or particle reactions, which require additional source terms for the scalars, 165 which couple with the liquid or solid phase. The following discussion concerns closure models and experiments for scalars primarily in the gas phase.

\subsection{Combustion closures}

Closures are traditionally grouped into a choice of 171 how the subgrid or fluctuating model handles diffusional 172 and reaction terms in Eq. 2. There are excellent recent reviews on the details of the many models and their usage, as detailed below; a guide to best practices to the use of these models has also recently appeared [12]. The next subsections briefly describe flamelet and $\mathrm{PDF} /$ micromixing models.

\subsubsection{Flamelet models}

Flamelet models assume that the time scales associated with chemical reaction are smaller those associated with turbulence. The conservation equations then allow the diffusion and reaction terms to be combined into a single entity, the flamelet, which can be transported convectively by the turbulent flow. Closure of the reaction term typically invokes a presumed PDF model, tied to conservation equations for the variance of the progress variable and mixture fraction, which gives rise to a term involving the subgrid scalar dissipation rate $\overline{\chi_{\psi}}=\overline{D_{\psi}|\nabla \psi|^{2}}$. The latter is finally related to the filtered or grid scale $\Delta$, a local turbulent viscosity (or reciprocal time scale $\tau_{\Delta}$ ) and a scalar variance, often via an algebraic closure, or modelled with corrections for reactive scalars. Flamelet models offer great simplification, by tying most scalars to a single progress variable $c$, which is transported by turbulence, and a local representation of the conserved atomic scalar in the form of a mixture fraction, $Z$. Reviews of models for premixed and non-premixed flamelets and variations thereof explain in greater detail how the progress of reaction is connected to other scalars via pre-calculated and tabulated flamelets [4, 7, 13, 15]. The key disadvantage of the method is of course associated with the assumption of the existence of a flamelet, which may not hold in situations such as autoignition, multiple streams or for scalars for which reacting time scales are larger than turbulent time scales. Even in these cases, however, extensions have allowed continuation where the model assumptions are broken, by using additional progress variables, in the case of slowly varying soot [16-18] or NO [19], or by using switching variables to capture the behavior of partially premixed flames [20, 21], or autoignition in lifted flames [22].

\subsubsection{Micromixing models}

Micromixing models, which encompass transportedPDF models, make no assumption regarding the ratio of time scales of reaction relative to turbulence time scales, are therefore applicable over any range of Damköhler or Karlovitz numbers. Simple micromixing models assume full or partial mixing within the subgrid scale, accompanied by reaction [1, 23]. Full transported 


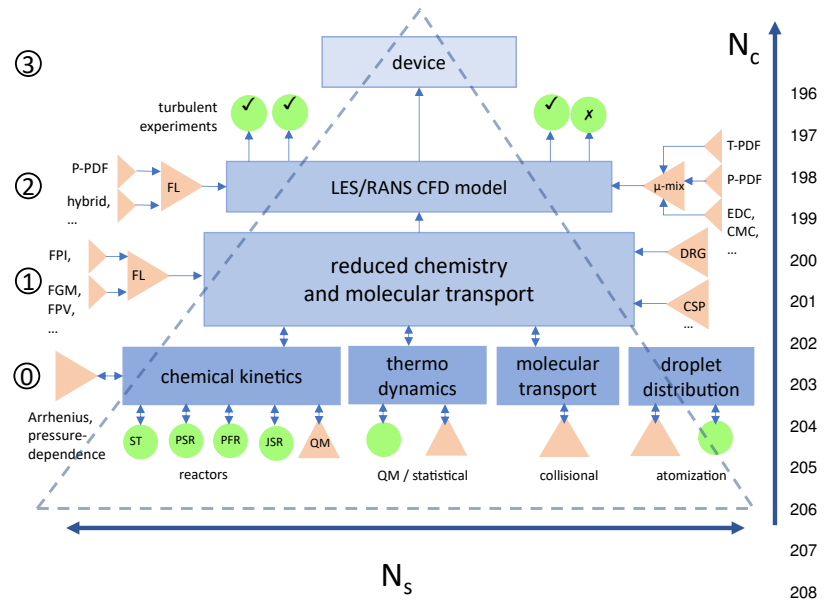

Figure 1: Hierarchy of model validation. Tan triangles: submodels; green circles: experiments. Numbered circles (left): validation 210 tier levels. Arrows: direction of information. $N_{c}$ : number of cells; 211 $N_{s}$ : number of scalars. Acronyms indicated are for the many de- 212 vices and methods used. Tier 0: PSR,PFR,JSR: perfectly stirred, plug flow and jet-stirred reactors; ST: shock tube; QM: quantum mechanical calculations. Tier 1: Example chemical reduction meth- 214 ods, including, FL: flamelet, FGM: flamelet generated manifold, FPV: 215 flamelet-progress variable; FPI: flamelet-progress indicator; DRG: di- 216 rected relation graphs; CSP: computational singular perturbation. Tier 2: large classes of flamelet (FL) or micromixing ( $\mu$-mix) models, for example: PDF: probability distribution function, T-PDF, P-PDF: 2 transported/presumed PDF; CMC: conditional moment closure, EDC: 219 eddy dissipation closure.
PDF approaches integrate equations for the evolution of the multivariable, single point PDF, but require models for closing the mixing term. The latter must resolve molecular diffusion at the smallest scales, a difficult task which can be achieved only by including ef- 225 ficient models of diffusion across the multidimensional 226 space [1, 4, 24, 25]). A number of simplified variants of PDF and stochastic models significantly reduce the dimensions across which diffusion occurs, for example one-dimensional turbulence [26], conditional or multiple mapping closures [27, 28], which lower the dimensionality of systems by projecting the dependence of species onto a small number of variables.

The need to control computational costs associated with these complex multiscalar, multiscale calculations generates a hierarchy of model validation, as discussed in the following sections.

\section{Hierarchical model validation}

Turbulent combustion models include models for ${ }^{241}$ chemistry and molecular transport, the associated heat 242 release, and turbulent transport, as outlined in Fig. 1 The size of the computational problem or system $N_{s}$ is 244 approximately proportional to the product of the num- 245 ber of cells in the system $N_{c}$, and the number of scalars involved in the system, $N_{s}$, defining the total computational time. There is therefore an inherent tradeoff between the achievable level of detail in the model, represented by $N_{s}$ and the geometric extent or detail $\left(N_{c}\right)$ for a given total duration of the simulations. In order to accomplish a simulation given a total available computational resource, higher order models are simplified to a smaller number of scalars (or cells), requiring validation at each level moving up in the hierarchy. Validation starts from comparisons of chemical kinetic and thermodynamic models against fundamental experiments or quantum mechanical calculations (Tier-0), moving onto the generation of reduced chemical and transport models (Tier-1). At the lowest Tier, chemical and transport models can be very detailed, whereas the flow setup may be simple, such as a fully mixed device. A validation strategy between reduced order models against their more detailed counterparts with a larger number of scalars (e.g. using techniques for systematically reducing mechanisms) or a smaller number of cells (e.g. models for the PDFs of unresolved quantities, such as presumed or transported PDFs), ensures that the next step in the hierarchy can be taken with some assurance. The focus of the present paper is specifically on the validation of turbulent combustion models in (Tier-2), but it is useful to consider parallels and distinctions between the process of validation of chemical kinetics to the validation of turbulent combustion models.

\subsection{Tier 0 - Chemical kinetics, transport and thermo- dynamics}

Simulations and validation experiments often start by selecting the appropriate level of detail for the problem, from equilibrium to single-step reactions, to multistep reactions. There is a vast literature dedicated to the subject for a variety of fuels, and well established methods for composing and extracting chemical kinetic models from data emerging from shock tubes, jet stirred and plug flow reactors, as well as theoretical models [29, 30]. Periodic reviews of the available information are codified into comprehensively validated models for hydrocarbon oxidation for a variety of hydrocarbon fuels over a wide range of temperatures and pressures. Examples of well understood oxidation mechanisms are (a) the GRI mechanism for methane [31], (b) mechanisms for syngas oxidation [32], and (c) mechanisms for hydrocarbon autoignition [33-35]. However, reaction mechanisms and their rates are continually revised, with an optimal set of reactions and their constants produced in a feedback loop between experiments and models, 
informed by sensitivity analysis and uncertainty quan- 296 tification, to extract optimum parameters in the sense 297 of a feasible optimum set [30, 36]. Both the chemistry 298 and the thermodynamics for liquid and solid fuels are 299 less well studied than that of smaller hydrocarbons, al- 300 though there are a number of well established surrogate 301 models for diesel and gasoline surrogates used both for 302 flames and autoignition. Mechanisms for soot forma- 303 tion are significantly more complex, involving sectional 304 (size dependent) models, yet validation datasets for soot 305 are rarer than for hydrocarbons. Models for soot are al- 306 ways a low order model, representing the thousands of 307 species or classes thereof [37, 38]. Model reduction is 308 often necessary prior to incorporating into combustion 309 models, yet one must keep in mind how these models 310 were originally obtained, as well as simplified, lest they ${ }_{311}$ be used beyond their validation range. The final tar- 312 get of a turbulent combustion simulation may or may ${ }_{313}$ not be sensitive to the uncertainties in the chemical ki- 314 netic mechanism or thermodynamic model, yet system- 315 atic uncertainty quantification is rarely incorporated into 316 routine validation exercises.

\subsection{Tier 1 - Reduced models}

The purpose of validation at Tier 1 is to reduce the ${ }_{320}$ number of scalars that need to be carried to the next ${ }_{321}$ level, while still reproducing key results from the exper- 322 iments in Tier 0 , for example autoignition times, or from ${ }_{323}$ experiments in Tier 1, such as premixed flame speeds, ${ }_{324}$ extinction or ignition. Systematic methods of reduc- 325 tion and tabulation of chemical kinetic mechanisms, ei- 326 ther with or without molecular diffusion effects [14, 3941], produce reduced reaction mechanisms, or generate look-up tables as a function of the smaller set of scalars. 327 There are many methods of mechanism reduction, and 328 many variants thereof, denoted by acronyms in Fig. 1

A succint review of their features and merits is available ${ }_{329}$ in Ref. [42]. Reduced mechanisms for use in turbulent flow calculations are usually of order of tens of species for realistic geometries. However, a very large class of ${ }_{332}$ LES or RANS simulations for practical combustors re- ${ }_{3} 3$ lies on only one or two scalars - a progress of reaction ${ }_{334}$ and a mixture fraction, very successfully for the simu- 335 lation of flame species behavior. Extensions to incorpo- 336 rate the simulation of the slower species such as NO and ${ }_{337}$ $\mathrm{CO}$ are routinely included in the reduction mechanism 338 or tabulation [39, 43, 44].

\subsection{Tier 2 - Turbulent combustion measurements and model validation}

In Tier 0 and 1, the objective of the model valida- ${ }^{343}$ tion exercise is to obtain a minimum set of chemical ${ }_{344}$ kinetic parameters compatible with the existing thermodynamics and experimental datasets and their uncertainties. In Tier 2 validation, the objective is different. In general, one wishes to benchmark an existing physical representation of turbulent combustion against a set of conditions of interest, and demonstrate that the target measurands agree with the predictions within acceptable bounds. However, the feedback loop between the error found and required changes to the model is not necessarily obvious. A robust model should have a minimum and transparent number of adjustable constants, and be validated against target experiments over a sufficiently wide range of conditions. These constants are are generally associated with the subgrid models, either directly as parameters in the adjustment of scalar dissipation or turbulent viscosities, apparent turbulent Schmidt numbers or other factors. If model parameters need to be changed depending on the conditions or the model chosen, its broader utility is lost.

Researchers have used benchmark experiments to reexamine model assumptions and alter them, relaxing strong assumptions, reviewing correlations or considering originally neglected terms in equations. Given the variety of assumptions used for subgrid models, the particular adjustments made can easily get lost in comparisons that may have different simulation details, such as mesh distribution. Published model validations almost invariably claim acceptable agreement with the experiments, yet the value of comparisons lies in understanding the modes of failure, and creating methods for dynamically determining an optimum model choice.

\section{A brief history of validation experiments for tur- bulent reacting flows}

Validation experiments for combustion have a long and distinguished history. This review considers samples of experimental datasets over the past 20 years which have served as beacons for modelling efforts. Given the need for statistical information for the models, time and space resolved measurements are required, particularly regarding correlations between the state space of temperature and species. Pope [45] suggested in a 1985 review that the experimental techniques of laser-Doppler-anemometry (LDA) and Raman spectroscopy were approaching the stage where simultaneous measurements of local instantaneous velocities and scalars would soon be possible, allowing probability models to be directly validated. As ever, one tends to overestimate the coming speed of technical change, yet there are promising developments afoot. 
A vast set of measurements have been produced for 395 turbulent flames, but only a subset of those is suffi- 396 ciently detailed to address some of the questions re- 397 garding the suitability of the turbulence-chemistry and 398 turbulence-diffusion model. One of the purposes of ex- 399 periments at this level is to provide data to test the hy- 400 potheses set out in models, or at least the results of the 401 hypotheses. In particular, assumptions in the models 402 posit inherent conditional relationships between scalars, 403 particularly between temperature and species. Whereas 404 it is always possible to test models a posteriori based 405 on the final mean or fluctuation measurements, the 406 power of detailed, single shot experiments which pro- 407 vide species-temperature and/or velocity-species statis- 408 tics lies in the ability to test out assumptions in the 409 model-based correlations between scalars under a range ${ }_{410}$ of conditions. Table 1 provides a non-exhaustive col- 411 lection of experiments produced for model validation, 412 including a variety of flame types, but focusing on sets 413 that are sufficiently complete to be useful, thus provid- 414 ing a broad sample of validation datasets that explore 415 the variety of flame structures. A number of experi- 416 ments on stratified flames listed on Table 1 also extend ${ }_{417}$ into purely premixed flames, but a much larger set of ${ }_{418}$ premixed experiments exists for a variety of configu- 419 rations of steady and unsteady premixed flames, as re- 420 viewed by [46], and in ongoing workshops on premixed 421 flame model verification and validation (e.g. [47]). $\quad 422$

\subsection{Tools of the trade}

The demand for measurements which can generate ${ }_{425}$ statistics of instantaneous species mass fractions and 426 temperatures for target gas flames requires specialized ${ }_{427}$ Raman, Rayleigh, laser induced fluorescence (LIF) or 428 coherent anti-Stokes Raman scattering (CARS) mea- 429 surements. Unlike the case of velocity measurements, 430 which require significantly less expertise, only three or 431 four well-equipped laboratories around the world have ${ }_{432}$ been able to maintain high-end facilities capable of ${ }_{433}$ accurate scalar measurements over the past couple of ${ }_{434}$ decades. Results are well documented through the TNF ${ }_{435}$ Workshop [115]: the work by Barlow and coworkers at ${ }_{436}$ Sandia National Laboratories, by Meier and colleagues ${ }_{437}$ at DLR Stuttgart, by Bilger and Masri at Sydney, and ${ }_{438}$ Dreizler and others at TU Darmstadt, as previously re- ${ }_{439}$ viewed in [116, 117]. The collaborative workshop has 440 inspired similar initiatives in engine [118], autoignition ${ }_{441}$ [119], and soot research [120].

\subsection{A smorgarsbord of flames}

Flames investigated at the turn of the $20^{\text {th }}$ century 445 were simple diluted turbulent jet diffusion and partially 446 premixed flames with jet Reynolds numbers from 10 to $40 \times 10^{3}$, as shown in the first block of Table 1 The original questions were associated with the ability of variants of flamelet and PDF models to reproduce the flame structure. These experiments offered point measurements with a resolution of hundreds of micrometers, time resolutions of sub-microseconds, and species and temperature accuracies between 1 and 10 percent, which is in general a useful engineering range for model validation.

The use of jet flames simplifies simulations for two reasons: (a) boundary conditions are simple, (b) the calculations are parabolic, so that the upstream values do not depend on downstream values, allowing calculation domains to be reduced based on computational resources, without prejudice to accuracy [12]. However, unpiloted jet flames cannot be stabilized beyond a critical velocity. Piloting is therefore adopted to support a number of the flames with higher jet velocities without full extinction. The pilot stream temperatures therefore had to be well characterized, and any differences in molecular weights and properties accounted for or tailored to match the main mixture gases.

In particular, a series of lean-pilot, partially premixed jet flame experiments led by Sandia [52, 53, 121] (series D-F) have been simulated by a vast number of researchers. The attraction appeared primarily because these measurements offered not only a full set of scalars, but also quantitative $\mathrm{NO}$ and $\mathrm{OH}$ measurements. Further, high velocity jets for flames E-F allow testing of models for localized extinction, so these flames continue to be benchmarks for models to this date [43, 122, 123]. A number of additional measurements were made in both the Sandia and DLR flames, including measurements of 2D and 3D fluctuating scalar dissipation of the mixture fraction [53, 121, 124], which allowed an examination of model assumptions and the role of filtering in the comparison of LES and models. A parallel series of flames from the Sydney group were investigated [54-56], with a number of variants on non-premixed jet flames, including bluff-body and swirl-stabilized flames which remained stable up to higher velocities, thus pushing $\mathrm{Re}$ and Ka numbers to higher levels and extinction arises. Swirl and bluff-body flames are of course more challenging from the fluid mechanics viewpoint, and can possibly create difficulties with the onset of higher heat transfer at the base. Many of these results are expressed in scatter plots of temperature-mixture fraction, which are useful for limits of diffusion-like flames.

Piloted high velocity non-premixed flames can be pushed to the point where they are lifted. In that case, 


\begin{tabular}{|c|c|c|c|c|}
\hline Name & Ref. & Description & Fuel & Measurements $^{a}$ \\
\hline \multicolumn{5}{|c|}{ Jet non-premixed and partially premixed } \\
\hline TUD-H3 & 48 & diluted non-premixed jet flame & $\mathrm{H}_{2}, \mathrm{~N}_{2}$ & $T, Y_{\mathrm{NO}}, Y_{\mathrm{OH}}$ \\
\hline $\mathrm{H} 2-\mathrm{A}, \mathrm{B}, \mathrm{C}$ & {$[49$} & diluted non-premixed jet flame & $\mathrm{H}_{2}, \mathrm{He}$ & $T, Y_{\mathrm{NO}}, Y_{\mathrm{OH}}$ \\
\hline DLR-A,B & [51] & piloted non-premixed jet flame & $\mathrm{CH}_{4} / \mathrm{H}_{2} / \mathrm{N}_{2}$ & $T, Y_{i}, Y_{\mathrm{NO}}, Y_{\mathrm{OH}}, \mathrm{CH}, U, V$ \\
\hline Sandia-C,D,E,F & \begin{tabular}{|l|l|}
52 & 53 \\
\end{tabular} & lean piloted jet partially premixed flame & $\mathrm{CH}_{4}$, air & $T, Y_{i}, Y_{\mathrm{NO}}, Y_{\mathrm{OH}}, U, V$ \\
\hline Sydney PF,BF,SM & \begin{tabular}{|l|l|}
54 & 56 \\
\end{tabular} & bluff-body and swirl stabilized flames & $\mathrm{CH}_{4}, \mathrm{CO}, \mathrm{H}_{2}$, methanol & $T, Y_{i}, Y_{\mathrm{NO}}, Y_{\mathrm{OH}}, U, V$ \\
\hline AJHC & 57 & piloted non-premixed jet flame & $\mathrm{CH}_{4}, \mathrm{H}_{2}$ & $T, Y_{i}, U, V$ \\
\hline DJHC & [58 & piloted non-premixed jet flame & $\mathrm{CH} 4$ (NG) & $T, Y_{i}, U, V, \mathrm{OH}, \mathrm{NO}$ \\
\hline \multicolumn{5}{|c|}{ Autoigniting/large pilot } \\
\hline Cabra & \begin{tabular}{|l|l|}
59 & $60]$ \\
\end{tabular} & rich piloted partially premixed & $\mathrm{H}_{2}, \mathrm{CH}_{4}$ & $T, Y_{i}, Y_{\mathrm{NO}}, Y_{\mathrm{OH}}$ \\
\hline PPJB & \begin{tabular}{|l|l|}
61 & 62 \\
6
\end{tabular} & lean premixed jet into large pilot & $\mathrm{CH}_{4}$ and $\mathrm{NG}$ & $T, Y_{i}, Y_{\mathrm{OH}}, \mathrm{CH}, \mathrm{CH}_{2} \mathrm{O}, U, V$ \\
\hline DJHC-2 & 63.65 & piloted premixed jet & $\mathrm{CH}_{4}, \mathrm{H}_{2}$ & $T, Y_{i}, Y_{\mathrm{NO}}, U, V$ \\
\hline \multicolumn{5}{|c|}{ Premixed and stratified } \\
\hline TUD stratified & 66 67 & concentric stratified flame, inner pilot & $\mathrm{CH}_{4}$ & $T, Y_{i}, U, V$ \\
\hline TUD counterflow & 68 & opposed flow turbulent flame & $\mathrm{CH}_{4}$ & $T, Y_{i}, U, V, \mathrm{OH}$ \\
\hline Cambridge stratified & \begin{tabular}{|l|l|}
69 & 70 \\
\end{tabular} & radially stratified flames with/without swirl & $\mathrm{CH}_{4}$ & $T, Y_{i}, U, V, \mathrm{OH}$ \\
\hline Sydney stratified & $\begin{array}{lll}71 & 75 \\
\end{array}$ & piloted burner with variable radial stratification & & $\mathrm{CH}_{4}, T, Y_{i}, U, V, \mathrm{OH}$ \\
\hline \multicolumn{5}{|l|}{ Sooting flames } \\
\hline DLR/Adelaide & {$[76-78]$} & lifted non-premixed jet flame & $\mathrm{C}_{2} \mathrm{H}_{4}$ & $T, U, V, f_{v}, d_{p}$ \\
\hline DLR/Adelaide-2 & \begin{tabular}{|l|l|}
55 & 79 \\
\end{tabular} & bluff-body non-premixed jet flame & $\mathrm{C}_{2} \mathrm{H}_{4}$ & $f_{v}$ \\
\hline Missouri & 80 & non-premixed jet flame (no co-flow) & $\mathrm{C}_{2} \mathrm{H}_{4}$ & $f_{v}$ \\
\hline DJHC-3 & \begin{tabular}{|l|l|l|}
58 & 81 & 82 \\
\end{tabular} & piloted jet flame & NG & $Y_{i}, U, V, \mathrm{OH}, f_{v}$ \\
\hline DLR/RQL & 83.85 & $\begin{array}{l}\text { swirling pressurized flame with secondary air } \\
\text { injection }\end{array}$ & $\mathrm{C}_{2} \mathrm{H}_{4}$ & $T, \mathrm{OH}, f_{v}, U, V$ \\
\hline \multicolumn{5}{|l|}{ Technical flames } \\
\hline TECFLAM & 86 & $\begin{array}{l}\text { model swirling injector, radial vanes, partially } \\
\text { premixed burner, operated at high } \mathrm{P}, \mathrm{T}\end{array}$ & $\mathrm{CH}_{4}$ & $T, Y_{i}, U, V, \mathrm{OH}$ \\
\hline GTMC & 89.92 & $\begin{array}{l}\text { model swirling injector, radial vanes, partially } \\
\text { premixed burner, also operated at pressure and } \\
\text { under instabilities }\end{array}$ & $\mathrm{CH}_{4}$ & $T, Y_{i}, U, V, \mathrm{OH}, \mathrm{CH}$ \\
\hline Siemens SGT-100 & 93 & $\begin{array}{l}\text { Siemens swirling injector, radial vanes, partially } \\
\text { premixed burner, operated at high } \mathrm{P}, \mathrm{T}\end{array}$ & $\mathrm{CH}_{4}(\mathrm{NG})$ & $T, Y_{i}, U, V, \mathrm{OH}, \mathrm{NO}$ (ave.) \\
\hline NASA LDI & 96 & $\begin{array}{l}\text { swirling lean direct injector operated on gas at } \\
\text { high P, T }\end{array}$ & $\mathrm{H}_{2} / \mathrm{CH}_{4}$ & $Y_{i}$ \\
\hline \multicolumn{5}{|l|}{ Spray flames } \\
\hline UC Irvine & 97 & pressure spray hollow cone atomiser flame & methanol & $U_{d}, V_{d}, n_{d}, d_{d}$ \\
\hline NIST & 98 & pressure spray hollow cone atomiser flame & methanol & $U_{d}, V_{d}, n_{d}($ dye $), d_{d}$ \\
\hline CNRS Orleans & 99] & $\begin{array}{l}\text { air-assist injector with surrounding co-flow; pilot } \\
\text { flame located at variable height from injector }\end{array}$ & n-heptane & $U_{d}, V_{d}, n_{d}, d_{d}, U, V$ \\
\hline Yale & 100 & $\begin{array}{l}\text { weakly turbulent jet with dilute droplets in } \\
\text { co-flow, stabilized at the atomiser tip }\end{array}$ & methanol & $T, U_{d}, n_{d}, d_{d}$ \\
\hline Sydney & \begin{tabular}{l|l|l|l|l|l|l}
101 & 102 \\
\end{tabular} & $\begin{array}{l}\text { dilute and dense spray into pilot mixture for } \\
\text { autoignition study into piloted co-flow }\end{array}$ & ethanol,methanol & $U_{d}, V_{d}, n_{d}, U, V$ \\
\hline Sydney-2 & 103104 & $\begin{array}{l}\text { weakly turbulent jet with dilute droplets in } \\
\text { co-flow, stabilized at the atomiser tip }\end{array}$ & acetone,ethanol & $U_{d}, V_{d}, n_{d}, \mathrm{OH}$ \\
\hline Cambridge swirl & \begin{tabular}{|l|l|}
105 & 106 \\
\end{tabular} & swirling confined spray flame & diesel, JP-10, PME, RME & $U_{d}, V_{d}, n_{d}, U, V$ \\
\hline Cambridge jet & 107 & bluff-body stabilized spray flame & $\begin{array}{l}\text { n-heptane,n-decane,n-dodecane, } \\
\text { jet-A1 }\end{array}$ & $\mathrm{CH}_{2} \mathrm{O}, \mathrm{OH}, \mathrm{Mie}$ \\
\hline Cambridge pilot & 108 & piloted bunsen burner with dispersed droplet mist & ethanol & $\mathrm{CH}_{2} \mathrm{O}, \mathrm{OH}, \mathrm{Mie}$ \\
\hline CORIA & \begin{tabular}{|l|l|}
109 & 110 \\
\end{tabular} & $\begin{array}{l}\text { confined burner at elevated temperature, } \\
\text { non-swirling air flow }\end{array}$ & ethanol, methanol & $U_{d}, V_{d}, n_{d}, \mathrm{OH}$ \\
\hline DHSC & \begin{tabular}{|l|l|}
111 & 112 \\
\end{tabular} & piloted spray flame into co-flow of air or lean pilot & ethanol & $T, U_{d}, V_{d}, n_{d}, U, V$ \\
\hline DLR & \begin{tabular}{|l|l|}
113 & 114 \\
\end{tabular} & high pressure and temperature spray flame & $U_{d}, V_{d}, n_{d}$ & \\
\hline
\end{tabular}

$Y_{i}$ : stable species concentrations, $n_{d}$ : droplet concentration, $d_{d}$ : droplet diameter, $\mathrm{OH}, \mathrm{CH}$ : non-quantitative PLIF, $f_{v}$ : soot volume fraction., NG: natural gas.

Table 1: Turbulent flame experiments offering quantitative statistics of species and temperature for flame structure validation.

entrainment and autoignition at the base of the flame ${ }_{457}$ can become a significant mechanism for flame stabiliza- 458 tion. This is a particularly difficult phenomenon to cap- 459 ture with simple flamelet models, and has been a desir- 460 able target flame of modellers as a challenge, either as a ${ }_{461}$ lifted non-premixed flame (Cabra burner) [59], or a series of lower speed autoigniting piloted flames [57, 58], ${ }^{462}$ or stratified-premixed autoigniting jet flames [61, 62].

Emerging needs in the validation of premixed and ${ }_{465}$ partially premixed flames for practical gas turbine flame 466 models led to a number of investigations, starting from very simple, controlled turbulence stratified flames within flammability limits [66, 67, 69, 70] to piloted rich flames with a more aggressive variance in mixture fraction [71-75].

Demand for accurate data sets on the formation of soot have spurred investigators to adapt previously used turbulent jet flames as benchmarks for soot production [55, 76-82], both at atmospheric pressures and more recently, up to 5 bar [83-85]. In these experiments, 
flame temperatures are measured using CARS, laser- 517 induced incandescence (LII) and absorption measure- 518 ments are used for determining soot volume fraction. 519 Very high pressure measurements from sprays at well 520 characterized diesel-like conditions are available in the ${ }_{521}$ ECN database [118]. There are currently no datasets 522 for steady turbulent soot formation for liquid sprays at ${ }_{523}$ high pressures, although it is understood that there are ${ }_{524}$ specific datasets for industrial injectors (e.g. [125]). ${ }_{525}$

A small number of flames that are surrogates for real ${ }_{526}$ gas turbine flames have been well characterized both at ${ }_{527}$ low pressure and high pressure and temperature by the ${ }_{528}$ TUD [86, 87] and DLR groups [88-95], as well as more ${ }_{529}$ recent experiments at NASA facilities [96]. These very 530 detailed measurements of technically premixed, realis- 531 tic burners demonstrate the state of the art for experi- ${ }_{532}$ mental investigations in industrially relevant flames. As ${ }_{533}$ discussed further on, realistic simulations of these sys- ${ }^{534}$ tems provide a glimpse into what has (or has not) yet 535 been solved for practical problems of this nature.

\subsection{A sprinkle of data}

Whilst there are many examples of turbulent premixed, partially premixed and non-premixed flames, 539 there is a dearth of good data sets on well-controlled and ${ }_{540}$ characterized spray flames, where experimental meth- ${ }_{541}$ ods have barely scratched the surface of what is needed ${ }_{542}$ and possible. Most of the flames currently used for ${ }_{543}$ benchmarking simulations have used pressure atomiz- ${ }_{544}$ ers mounted centrally, surrounded by a co-flow, and ${ }_{545}$ measurements of droplet sizes and velocities was made ${ }_{546}$ using phase-Doppler anemometry (PDA) [97, 98, 105, 547 107, 126]. Some measurements have aimed to decou- ${ }_{548}$ ple the spray atomization process from the transport and ${ }_{549}$ combustion by producing controlled mists [99, 101- 550 104]. More recently, well-controlled piloted spray mea- ${ }_{551}$ surements have also been produced [111, 112]. Only ${ }_{552}$ a few of those many experiments provide gas velocity ${ }_{553}$ measurements as well as droplet velocities, and only ${ }_{554}$ two data sets have produced detailed temperature mea- ${ }_{555}$ surements using CARS. The ECN network [118] has ${ }_{556}$ been creating a consistent database for diesel-like and ${ }_{557}$ gasoline sprays over a range of conditions suitable for ${ }_{558}$ validation, and that activity should start to populate the ${ }_{559}$ necessary space for robust modelling of these phenom- 560 ena.

A number of high quality experiments exist as part 562 of a more general database, including a wealth of data ${ }_{563}$ on steady and unsteady premixed flames as reviewed ${ }_{564}$ in [46], and a growing database of imaging of pre- 565 mixed flames at high Karlovitz numbers [10, 127] which 566 can be modelled directly via DNS [128]. More practically, there is also an emerging database on oxyfuel/coal flames [129, 130], and many experiments on high frequency visualization of combustion instabilities and limit phenomena, for example [131-134], which are not addressed in the present review.

From this brief survey, we conclude that there is a large variety of test cases offering pointwise scalar and velocity information at atmospheric pressure, ranging from diffusion to partially premixed flames, with and without pilot, and near and away from autoignition. A few experiments also have information on relevant pollutants. There is a much smaller database at high pressures and temperatures, typically containing information on more practical flames. The detailed database on scalars in sprays flames is very small, and almost non-existent at pressure. Given the importance of liquid phase combustion for practical applications, including engines and aeroengines, this state of affairs appears to reflect the ingenuity of engineers, who continue to produce good products with incomplete information.

\section{Minding the gap: the state of the art}

Guidelines on model validation [12, 135] in general offer the following advice: (a) validation experiments should be designed independently, but considering input from modellers, (b) boundary conditions should be well characterized, and their influence quantified, (c) random and systematic experimental uncertainties should be clearly assessed, (d) a hierarchy of experimental measurements of increasing computational difficulty and specificity should be created, from globally integrated quantities to local quantities, (e) validation should be attempted over a wide range of conditions to which model parameters are sensitive. As a final guideline, not sufficiently emphasized in previous studies, (f) validation should be conducted by modeling the quantity directly experimentally measured (say, scattered signal or speed of sound), rather than the variable in the governing equations (e.g. temperature). The fact that the customer is usually the modeler leads to convoluted attempts by experimentalists at inversion of the experimental signal, adding to the error in the final delivered measurand.

The experiments listed in Table 11 were most frequently designed by experimentalists, with input from modellers, to test robustness of turbulent combustion models. However, reality often intervenes to complicate what initially seems a simple task to measure boundary conditions: effects of heat transfer back to the stabilization point, or the role of boundary layers upstream con- 
spire to add uncertainty to otherwise well-designed experiments [136]. Random errors are usually assessed by understanding the limitations of the optical diagnostic techniques used; yet systematic errors (typically associated with flow measurements, instrument calibration or asymmetry) are often much more difficult to assess, and are only discovered in the rare occasions when an experiment is duplicated elsewhere. Finally, the measurement of local rates or terms in balance equation is possible only in the simplest of cases - but there is certainly room for thoughtful experiment design to target specific model features, as highlighted in Section 6 . In what follows, we consider a few examples of cross comparisons between models and experiments, which capture the advances in prediction, and suggest a future path.

\subsection{Rich premixed-diffusion Sandia flame $D-F$}

An entire tome could be written on the roughly 400 comparisons of models and experiments of piloted partially premixed flames D-F associated with the TNF Workshop [115]. These sets have often been selected for validation, as they offer not only stable species measure- ${ }^{618}$ ments, but also NO and $\mathrm{OH}$ concentrations. The nature ${ }^{619}$ of the flame, consisting of a rich stream $\left(25 \% \mathrm{CH}_{4}, 75 \%\right.$ air, for $\phi=3.17$ ), surrounded by a lean pilot flame, produces a well-controlled environment for the simulation of flames exposed to high turbulence levels into near ex- 622 tinction. Many LES simulations are able to capture the 623 behavior of major species, velocities and temperatures 624 with modest spatial resolution, and a range of subgrid 625 models. Most LES (and RANS) models are able to cap- 626 ture the overall temperature and velocity distributions 627 using tabulated or flamelet approaches, although the be- 628 havior of the higher velocity flames E-F are more chal- 629 lenging for coarser models [43, 137]. Creative solutions 630 - for example by the introduction of additional scalars 631 with reacting time scales uncoupled to the lead progress 632 variable - are used in combination with flamelet models 633 to capture extinction behavior, as well as the concentra- 634 tions of the slower reacting species $\mathrm{CO}$ and NO further 635 downstream. A concise review of a number of simu- 636 lations of NO in flame D using tabulation and direct ${ }_{637}$ chemical integration approaches is available in Refs. ${ }^{638}$ [43, 137]. Figure 2 shows a collection of simulation results for NO centerline concentrations, both recent ${ }^{639}$ and past, using direct integration and extended flamelet 640 models. Prediction of NO mass fractions using flamelet 641 modes requires inclusion of an additional variable to ac- 642 count for disparate time scales as well as accounting for 643 subgrid variances, as demonstrated by [44, 138]. In con- 644 trast with flamelet models, RANS-PDF models tend to 645 be quite successful in representing the chemistry of slow 646

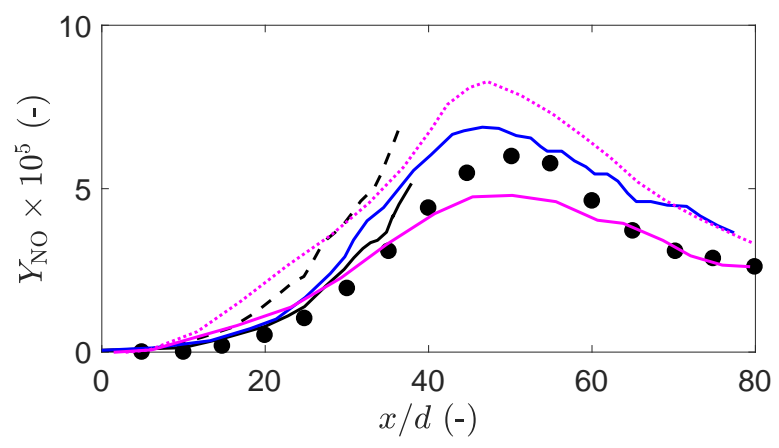

Figure 2: Sample LES simulation and experimental results for Sandia Flame-D using directly integrated chemistry. Symbols are experimental mass averaged mixture fractions along the centerline. Black lines from [43]: Highly resolved (2-5 $\left.\ell_{k}\right)$ direct integration simulations using GRI2.11 (solid), and GRI3.0 (dashed lines). Blue lines from [140]: (40 $\mu \mathrm{m}$ grid, tabulated premixed flamelet-PSR model. Magenta lines from [138]: premixed flamelet, coarse grid $(D / 8)$, with scalar subgrid variance (solid) and with thickened flame model (dashdotted).

reacting species, as shown for example in earlier papers by Tang et al. [139], as well as autoigniting flames discussed below.

\subsection{Autoigniting flames}

Predictions regarding the interaction between high velocity reactants and surrounding pilot flames challenges simpler models, as the combustion regime becomes a mixture between autoigniting reactants under partial diffusion control. PDF transport models [25, 141] and CMC [142, 143] as well as RANS-PDF [144] with reduced chemistry have been used to model these systems to predict scalar profiles. Creative approaches to modelling these flames by using a switching index which can recover either the diffusion, premixing or autoigniting regimes, and still use unsteady flamelets and tabulation using PFR or PSRs [22, 145, 146]. The good performance of flamelet models under these conditions is perhaps surprising, but as has been noted [22, 145], autoignition times are not very sensitive to the particular diffusion model used, rendering predictions rather forgiving of the particular details.

\subsection{Stratified flames and technically premixed flames}

The Cambridge and TU Darmstadt stratified flames have been the targets of a number of validation efforts [21, 147-149]. Results on the Darmstadt simulation results were recently compiled by Fiorina et al. [136], showing that stratified flames within the flammability limit behave essentially as ensembles of premixed flames. The state of the art in understanding 


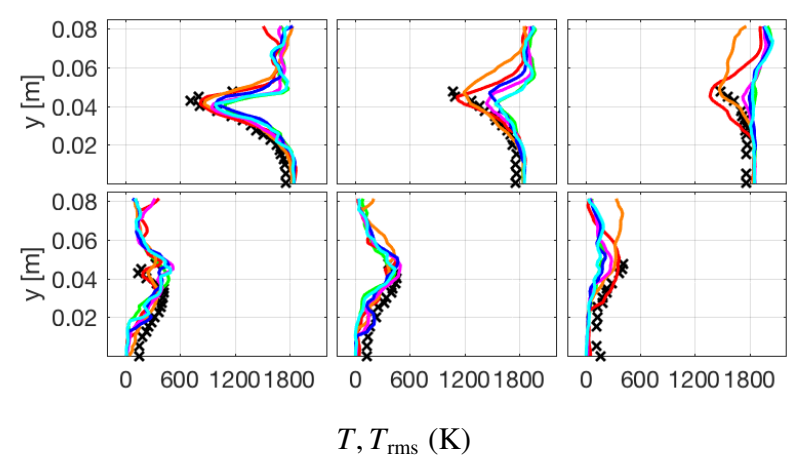

Figure 3: Sample comparison of measured and predicted mean temperature (top) and corresponding RMS fluctuations (bottom) on a 7 Mcell grid model of the SGT-100 burner experiments, for distances from the burner of $x / D=[1.21,1.44,1.66]$. Legend: $(-)$ LES-PaSR, $(-$ ) LES-EDC, (-) LES-FM, (-) LES-TFM, (-) LES-SF, (-) LES-ADM and (+) experimental data from [93. 95. For references to the details 678 of each model, the reader is referred to the original paper [153]. of such flames has been recently reviewed and dis- ${ }^{681}$ cussed in [150]. A recent series of rich-piloted strati- ${ }^{682}$ fied flames by [71-75] offer an interesting case where ${ }^{683}$ both premixed and diffusion behavior are simultane- 684 ously present, based on the correlation of temperature ${ }^{685}$ and mixture fraction. A number of papers in this Sym- ${ }^{686}$ posium address the difficulties in these simulations. ${ }_{687}^{687}$

Measurements and simulations of technically pre- ${ }^{688}$ mixed flames under high pressure and temperature have 689 been made, mostly on generic gas turbine injectors with 690 natural gas, as listed in Table 1. but also on a variety of 691 swirl-stabilized burners, as reported in [151, 152] and 692 others, where the dataset may not be complete owing 693 to proprietary or other reasons. Recent simulations by 694 [153-155] of the Siemens SGT-100 burner experiments 695 [93-95] have benchmarked a variety of models against a 696 whole range of simulations. Fedina et al. [153] analyzed ${ }^{697}$ the results of six variations of micromixing and flamelet 698 models, concluding that the overall error in tempera- 699 ture, velocity and major species across the four cross 700 sections of the flame were similar for all models, as 701 shown in Fig. 3. Previous LES results using a simple 702 eddy closure model against the same dataset showed an overprediction of both outlet NO and CO by a factor 703 of about four, whereas more recent predictions of the same flame using integration of reduced chemical mechanisms [154, 156] showed results within 25 percent of the measured values.

\subsection{Sooting flames}

Simulations of turbulent sooty flames have existed, 710 but only recently have reliable detailed comparisons 711

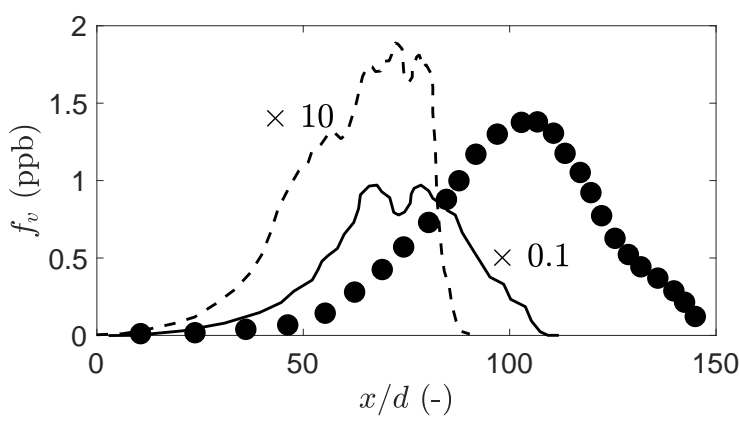

Figure 4: Comparison of experimental measurements of mean soot volume fraction (circles) at the centreline of the flame in [81], simulations [158] and [159] (note different scales for model results).

been made between measurements and experiments. The DJHC-3 flame [58, 81, 82] has been simulated using LES coupled with presumed-PDF methods, with additional closures to account for the population balance for soot volume and area, and global models for PAH growth [157] based on the literature. Donde et al. [158] and Sewerin and Rigopoulos [159] used a PDF/population balance with stochastic closures to model the same flame. In all cases, agreement with major species and temperature is good, but estimates of soot volume fraction spread over two orders of magnitude, as shown in Fig. 4 Recent comparisons with the experimental data from DLR in [83, 84] show encouraging results for high pressure predictions of soot. Clearly, significantly more work is needed in refining models, as well as identifying potential measurements which could identify the problems. Recent measurements [160] of mixture fraction using $\mathrm{Kr}$ fluorescence showed an innovative means of obtaining simultaneous soot and mixture fraction, for example, and further measurements are certainly needed. The emerging measurements from the ECN network on soot formation in engines, as well as other unsteady measurements [161] of mixture fractions in unsteady jets will continue to help improve models and their accuracy.

\subsection{Spray combustion}

A recent review of models for dilute sprays, provides an excellent summary of the issues surrounding spray simulations, including those of the Delft hot spray flame (DHSC) ([111, 112]). The latter experiments provide a more complete database than similar studies, and several recent studies have tackled the simulation with good results using flamelet and transported PDF [162-164], as well as stochastic methods [165]. 
Sample results for two cases are shown in Fig. 5, one with co-flowing air, $A_{I I}$, and one with co-flowing pilot $\left(H_{I I}\right)$. The very interesting and complex structure of such flames, which feature multiple reaction zones owing to the inner and outer mixing regions, makes them a challenging choice, quite apart from the difficulties in simulating two-phase flows. Clearly, whereas the structure of the piloted spray is reasonably well captured, that is not the case for the air co-flow, and this case will continue to be the target of model investigations.

There have been many simulations of steady spray flames, from RANS simulations for practical fuels [166], to stochastic-LES simulations [167] of the early McDonell data [97], and CMC models [168] of wellcontrolled pressure-atomized flames [108], as well as countless simulations of high velocity, transient autoigniting jets such as those available in the ECN database [118]. Yet one of the striking observations about the list of steady spray measurements in Table 1 is that, unlike their gaseous counterparts, none have 762 reliable measurements of mixture fraction or species, 763 and only few have gas velocities and product tem- 764 peratures. The main reason for this lack of information is the significant background interference created by the highly radiative environment prevalent in sootladen or spray flames, which renders various incoher- 766 ent scattering-based techniques impossible to quantify. 767 Even robust velocity measurement techniques that rely 768 on Mie scatter tend to be affected by background noise 769 in highly radiative situations. These difficulties are com- 770 pounded at high pressures, as not only does the radia- 771 tive background signal increase, but so does the extent 772 of signal trapping for measurement techniques such as 773 laser induced fluorescence and laser-induced incandes- 774 cence. As a result, the database is limited, and mod- 775 els that try to reproduce the features of sooting, particle 776 or spray-laden flames can at best reproduce the behav- 777 ior of droplet sizes, concentrations and velocities, and 778 possibly the location of the flame by comparison with 779 $\mathrm{OH}$ measurements. Spray and soot combustion mod- 780 elling and measurements remain a challenge, and suit- 781 able datasets are clearly needed. Coherent optical tech- 782 niques offer a sensible way around some of the radiative 783 background problems, and the next section discusses 784 some emerging diagnostic possibilities.

\section{Experimental needs and opportunities}

The review of experiments outlined in Section 5 has 789 revealed some areas of agreement between models and 790 experiments, and some significant gaps. There are, of 791 course, as many experimental situations as one cares to 792
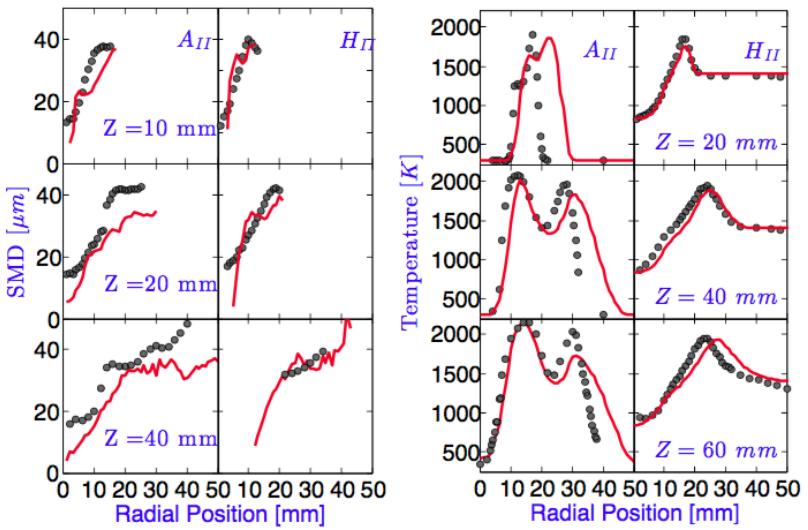

Figure 5: Radial profiles of droplet SMD (left), and mean temperature (right) at several elevations from the burner, for case $A_{I I}$ (air-spray) and $H_{I I}$ (pilot-spray). Line: LES results from [169], symbols: experimental data from [111]. Left: Sauter mean droplet diameter (SMD); right: mean temperatures.

invent, so the question is: where should one focus? Below we list some of the largest gaps, and suggest emerging techniques which could be used to address them.

\subsection{Spray and sooting flames}

Spray flames are luminous and soot-prone, so that the workhorse of measurements for temperature and species - Raman scattering measurements - does not work under these conditions. Ample data are available on droplet sizes and velocities, accompanied by occasional non-quantitative measurements of $\mathrm{OH}$ or $\mathrm{CH}_{2} \mathrm{O}$, which are helpful in terms of identifying flame structures, but not so useful for quantitative validation. Apart from the significant progress highlighted in Sections 5.4 and 5.5, there is a possible opportunity for new fs/psCARS techniques in these flames: unlike ns-CARS, these techniques have been demonstrated to be insensitive to both radiative background (since it is a coherent technique) as well as non-resonant background, and work well under sooting conditions [170--174]. Further, their applicability to 1D and 2D-CARS has been demonstrated, as well as wideband techniques that can extract multiple species [171, 175]. The disadvantage of these techniques at the moment is that they require significant specialist expertise, both in setting up the phasesensitive experiments, as well as in processing and interpreting the information. Modelling efforts need to pinpoint what type of information would be most critical to differentiate between models, keeping in mind the ultimate targets of the validation, whether that be with respect to emissions, heat release rate or other parameters. 


\subsection{Real hydrocarbons}

Most of the studies discussed above have used 842 methane, as it is the simplest hydrocarbon. Yet the ${ }^{843}$ different behavior of higher hydrocarbons is likely to have significant effects, particularly with respect to ef- ${ }^{845}$ fective Lewis numbers. Recent DNS work [176, 177] ${ }^{846}$ reveals how the complex chemistry of larger hydrocar- ${ }^{847}$ bon is translated onto the macroscale behavior of tur- ${ }^{848}$ bulent flames. Experimental work using Raman scatter- ${ }^{849}$ ing of hydrocarbons becomes more challenging as the ${ }^{850}$ the multiplicity of intermediate species creates interfer- ${ }^{851}$ ences in the spectral range. Yet detailed information has ${ }^{852}$ only started to emerge for turbulent flames containing ${ }^{853}$ some of the simpler, soot-free hydrocarbons [178-180].

\subsection{Realistic densities, realistic $\mathrm{Ka}$}

The vast majority of experiments have been performed at ambient conditions, yet most combustion devices operate at high pressure and temperature. The barriers are costs (which increase with confinement) and the quality of the measurements, which can suffer due to signal trapping, beam steering, and spectral broadening. Emerging techniques that provide higher signalto-noise at higher densities (such as laser induced grating spectroscopy [181]) or that are not prone to collisional broadening (ultra-fast techniques) may also help. However, as the discussion in Section 5 and Fig. 3 highlights, it is perhaps surprising that the overall flame ${ }^{86}$ structure can be relatively insensitive to the details of the micromixing model in some high turbulence cases. It would be useful to understand how general these findings might be in practical problems.

\section{Error and uncertainty analysis}

The process of model validation is usually considered ${ }^{874}$ finished when the error between measurements and sim- 875 ulations is quantified to be within the estimated exper- ${ }^{876}$ imental uncertainty. When discussing highly unsteady ${ }^{877}$ phenomena such as turbulent combustion, measures for 878 comparison are typically statistical averages and mo- 879 ments. In the case of instabilities, the quantity of in- 880 terest may be a characteristic time scale or spectrum. ${ }^{881}$ What is an appropriate measure of a validated model? 882 How sensitive is the error to model parameters? And ${ }^{883}$ how do we know whether models can be extrapolated 884 beyond the conditions where strict validation was con- 885 ducted?

The quantification of errors is a general problem ${ }^{887}$ associated with probabilistic outcomes in either mea- 888 surements or models, which has been tackled on the 889 modelling level via uncertainty quantification (UQ). A number of studies have used statistical methods for error propagation, particularly those associated with the extraction of reaction parameters [182-184], but also thermoacoustic oscillations [185, 186], and are general enough to, in principle, be applicable to any model parameter. Khalil et al. [183] have recently considered the sensitivity of results in a bluff-body flame to a range of model parameters, whilst Mueller and Raman [122] have considered uncertainties in different types of models. Although uncertainties in boundary conditions have been considered by trial and error, the methodology of polynomial expansion in UQ has been used recently for identifying uncertainties due to boundary conditions in spray simulations [187]. Finally, a recent contribution by Ihme and colleagues [188] applies systematic statistical error measurement methods to quantify the overall error for a number of variables in the recently investigated Sydney stratified flame [74, 75], allowing for a quantification of the influence of various predicted intermediate variables on the overall error, as shown in Fig. 6. Clearly, these methods are useful not only to identify the merits of different models, but also to understand the sensitivity of results to measured boundary conditions, to pinpoint cross-correlations, and to guide the models towards better physical representations.

\section{Designing future experiments}

Whereas UQ has been used to quantify the bounds of model uncertainty, and therefore the limits of error between model and experiments, the potential for UQ and error quantification techniques is much more relevant when applied to the design of experiments, by attempting to ask the following questions upfront:

1. What is the target output of the model? In other words, which predictions are most valuable: $\mathrm{CO}$ ? NO? Soot? Instability frequency? Rate of combustion? A combination of those with different weights? Over what range of conditions?

2. What qualifies a good test of a model or submodel? Changes to the model should yield differentiable outputs: when very different submodels give answers within the accuracy of the experiment, the model is not adequately tested.

3. How sensitive are the outputs of the model to the inherent errors in the experiment, for example to details of domain boundary conditions, such as velocity or temperatures?

4. To what extent can the model be confidently extrapolated away from validated ranges, given 


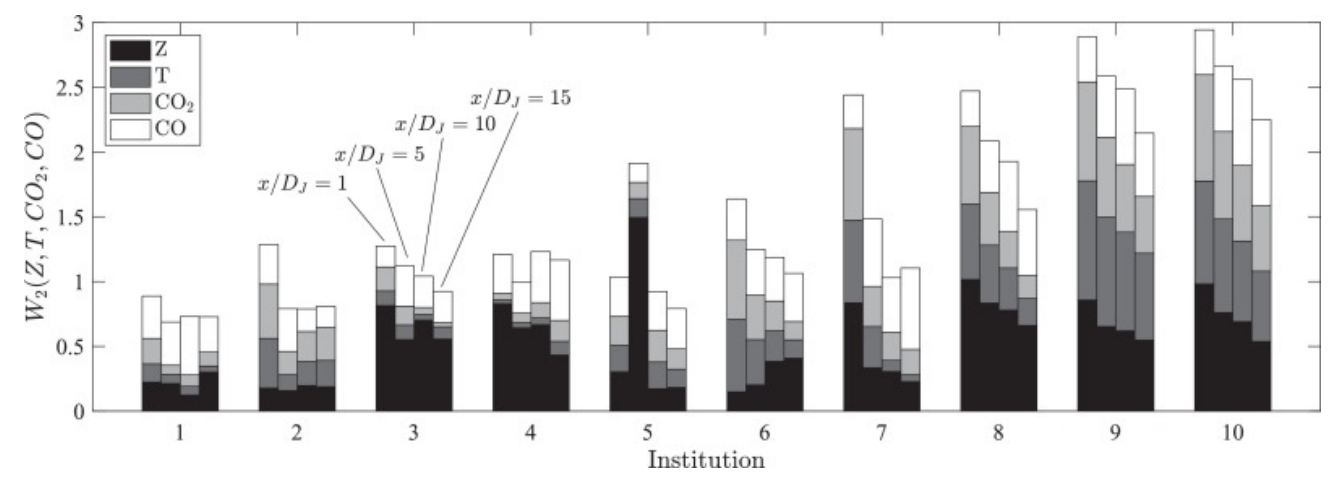

Figure 6: Quantitative comparison of multiscalar Wasserstein metric as a measure of global error [188], from ten anonymized LES-calculations, presented at the 13th TNF-workshop [115] for flame conditions FJ-5GP-Lr75-57 in the inhomogenous flame [72,75]. The decomposition of multiscalar calculations allows contributions from each variable at each axial location to become visible. The four bar-graphs from each contribution correspond to axial locations of $x / D_{j}=[1,5,10,15]$. Results used in this figure were included with permission from TNF-contributors. Reproduced from [188].

known uncertainties in scaling? For example, if ${ }_{922}$ the uncertainties in chemistry due to pressure are ${ }_{923}$ well bounded, what are the expected uncertainties ${ }_{924}$ of the turbulent predictions at pressure? Can these ${ }_{925}$ bounds be used to decide whether experiments are ${ }_{926}$ necessary or useful?

These are not technically straightforward questions, but surely worthwhile enterprises given the enormous effort devoted to developing experiments and to acquiring high quality data. Data generated by a validation effort can become significantly more valuable if the targets and sensitivities are clearly understood, and quantified. As well observed by Oberkampf and Trucano [135], decisions about model validation should take into account the various incentives in place for both experimentalists and modellers and their respective institutions, in evaluating the need for (or the results of) a validation exercise. A complex and challenging experiment from the point of view of the diagnostic developers may or may not yield the necessary results for the model. Similarly, complex or computationally-intensive simulations may or not answer the question of whether they are valid over the design range if the output sensitivity is insufficient.

\section{Summary: a more perfect union}

In this brief review, we collect a broad spectrum of validation experiments for turbulent combustion and 948 their respective comparisons, and suggest ways to im- 949 prove the productivity of validation procedures. Suc- 950 cess requires joint work between experimentalists and ${ }_{951}$ modellers to understand how to design validation pro- ${ }_{952}$ cedures that provide clear answers to well-posed ques- ${ }_{953}$ tions. The most referenced databases have demonstrated the following attributes: (a) well-defined geometries and boundary conditions, (b) accessible data, (c) a sufficient number of independent and complementary scalar and velocity measurements, over a wide enough parameter range, and (d) quantified uncertainties.

Examination of the state of the art in model validation shows that there are clear gaps in validation-quality data in spray, soot, and high pressure combustion. In that vein, there are opportunities for upfront collaboration between modellers and experimentalists to design experimental targets designed with a clear understanding of which model features can actually be tested and distinguished. Further, researchers would benefit from closer exchange in information with industry to better quantify the value of increasing accuracy of predictions for different target variables: how much is a marginal increase in accuracy in NO prediction worth, relatively to other potential quantities? These are challenging questions, yet understanding the value of improvements will help better allocate resources. A panel discussion at this Symposium will hopefully open up the questions raised to enlighten a wider audience.
4 每

\section{D}

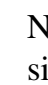
sightful comments and suggestions. The University of Cambridge provided access to bibliographical resources 
for the efficient search and compilation of this review, 1016 and allowed the use of my professional time for the pur- 1017 pose.

\section{References}

[1] S. B. Pope, Proceedings of the Combustion Institute 34 (2013) ${ }^{1023}$ $1-31$.

[2] T. Poinsot, D. Veynante, Theoretical and Numerical Combus- 1025 tion, CERFACS ELearning, 2012.

[3] N. Peters, Turbulent Combustion, Cambridge University Press, ${ }_{1027}$ 2000

[4] H. Pitsch, Annual Review of Fluid Mechanics 38 (2006) 453- ${ }^{1029}$ 482.

[5] P. A. Libby, Introduction to Turbulence, Taylor and Francis, ${ }^{103}$ 1996.

[6] P. A. Davidson, Turbulence: an introduction for scientists and ${ }^{103}$ engineers, Oxford University Press, 2015.

[7] N. Peters, Symposium (International) on Combustion 1 (1986) ${ }^{1035}$ 1231-1250.

[8] R. Borghi, Combustion and Flame 80 (1990) $304-312$

[9] N. Peters, Proceedings of the Combustion Institute 32 (2009) $1{ }^{1038}$ -25 .

[10] T. Wabel, A. Skiba, J. Driscoll, Combustion and Flame 188 (2018) 13-27.

[11] J. Oefelein, in: 53rd AIAA Aerospace Sciences Meeting, pp. ${ }^{1042}$ AIAA 2015-1378.

[12] R. Roekaerts, L. Vervisch (Eds.), Best Practice Guidelines for ${ }^{1044}$ Computational Fluid Dynamics of Turbulent Combustion, ER- ${ }^{1045}$ COFTAC, 2015.

[13] J. van Oijen, L. de Goey, Combustion Science and Technology ${ }^{1047}$ 161 (2000) 113-137.

[14] O. Gicquel, N. Darabiha, D. Thévenin, Proceedings of the ${ }^{1049}$ Combustion Institute 28 (2000) 1901 - 1908

[15] M. Ihme, H. Pitsch, Combustion and Flame 155 (2008) $70-{ }^{1051}$ 89.

[16] H. Pitsch, E. Riesmeier, N. Peters, Combustion Science and ${ }^{1053}$ Technology 158 (2000) 389-406.

[17] B. Franzelli, E. Riber, B. Cuenot, M. Ihme, in: ASME Turbo ${ }^{1055}$ Expo 2015: Turbine Technical Conference and Exposition, pp. ${ }^{1056}$ GT2015-43630.

[18] M. E. Mueller, H. Pitsch, Physics of Fluids 25 (2013).

[19] H. Pitsch, H. Steiner, Physics of Fluids 12 (2000) 2541.

E. Knudsen, Shashank, H. Pitsch, Combustion and Flame 1621000 (2015).

[21] S. Nambully, P. Domingo, V. Moureau, L. Vervisch, Combus- ${ }^{1062}$ tion and Flame 161 (2014) 1756-1774

[22] P. Domingo, L. Vervisch, D. Veynante, Combustion and Flame ${ }^{1064}$ $152(2008) 415-432$.

[23] B. Magnussen, B. Hertager, Proc. 16th Int. Symp. on Combus- ${ }^{1066}$ tion (1976) 719-727.

[24] D. Haworth, Progress in Energy and Combustion Science $36{ }^{106}$ (2010) 168-259.

[25] W. P. Jones, S. Navarro-Martinez, Combustion and Flame $150{ }^{1070}$ (2007) $170-187$.

[26] A. R. Kerstein, Journal of Fluid Mechanics (1999) 277-334 1072

[27] A. Klimenko, R. Bilger, Progress in Energy and Combustion ${ }^{1073}$ Science 25 (1999) 595-687.

[28] M. J. Cleary, A. Y. Klimenko, Flow, Turbulence and Combus- 1075 tion 82 (2009) 477.

[29] X. You, T. Russi, A. Packard, M. Frenklach, Proceedings of the ${ }^{1077}$ Combustion Institute 33 (2011) 509-516.

[30] M. Frenklach, A. Packard, P. Seiler, R. Feeley, Int. J. Chem. ${ }^{1079}$ Kinet. 36 (2004) 10.1002/kin.10172.
[31] G. P. Smith, D. M. Golden, M. Frenklach, N. W. Moriarty, B. Eiteneer, M. Goldenberg, C. T. Bowman, R. K. Hanson, S. Song, W. C. Gardiner Jr., V. V. Lissianski, Z. Qin, GRIMech, http://www.me.berkeley.edu/gri_mech/, 2000.

[32] A. Keromnes, W. Metcalfe, K. Heufer, N. Donohoe, A. Das, C.-J. Sung, J. Herzler, C. Naumann, P. Griebel, O. Mathieu, M. Krejci, E. Petersen, W. Pitz, H. Curran, Combustion and Flame 160 (2013) 995-1011.

[33] J. Andrae, Fuel 107 (2013) 740-748.

[34] Y. Ra, R. Reitz, Combustion and Flame 158 (2011) 69-90.

[35] C. Westbrook, W. Pitz, M. Mehl, H. Curran, Proceedings of the Combustion Institute 33 (2011) 185-192.

[36] D. Sheen, H. Wang, Combustion and Flame 158 (2011) 2358 2374.

[37] S. Roy, D. Haworth, Combustion Science and Technology 188 (2016) 1021-1053.

[38] H. Wang, Proceedings of the Combustion Institute 33 (2011) $41-67$.

[39] J. A. van Oijen, A. Donini, R. J. M. Bastiaans, J. H. M. ten Thije Boonkkamp, L. P. H. de Goey, Progress in Energy and Combustion Science 57 (2016) 30 - 74.

[40] T. Lu, C. Law, Proceedings of the Combustion Institute 30 (2005) 1333-1341.

[41] S. Lam, D. Goussis, Proc. Combust. Inst. 22 (1988).

[42] T. Lu, C. Law, Progress in Energy and Combustion Science 35 (2009) 192-215.

[43] T. Jaravel, E. Riber, B. Cuenot, P. Pepiot, Combustion and Flame 188 (2018) 180 - 198.

[44] M. Ihme, H. Pitsch, Phys. Fluids 5 (2008) 055110-055110-20.

[45] S. Pope, Progress in Energy and Combustion Science 11 (1985) 119 - 192

[46] J. F. Driscoll, Progress in Energy and Combustion Science 34 (2008) $91-134$.

[47] A. Comer, Model Validation for Propulsion Workshop, https://community.apan.org/wg/afrlcg/mvpws/, 2018.

[48] A. Neuber, G. Krieger, M. Tacke, E. Hassel, J. Janicka, Combustion and Flame 113 (1998) 198 - 211.

[49] R. S. Barlow, C. D. Carter, Combustion and Flame 97 (1994) $261-280$.

[50] R. S. Barlow, C. D. Carter, Combustion and Flame 104 (1996) $288-299$.

[51] W. Meier, R. S. Barlow, Y.-L. Chen, J.-Y. Chen, Combustion and Flame 123 (2000) $326-343$.

[52] R. S. Barlow, J. H. Frank, Symposium (International) on Combustion 27 (1998) 1087 - 1095.

[53] A. Karpetis, R. Barlow, Proceedings of the Combustion Institute 29 (2002) $1929-1936$.

[54] A. R. Masri, B. B. Dally, R. S. Barlow, C. D. Carter, Symposium (International) on Combustion 25 (1994) 1301 - 1308.

[55] B. Dally, A. Masri, R. Barlow, G. Fiechtner, Combustion and Flame 114 (1998) 119 - 148.

[56] P. A. Kalt, Y. M. Al-Abdell, A. R. Masri, R. S. Barlow, Proceedings of the Combustion Institute 29 (2002) 1913 - 1919.

[57] B. B. Dally, A. N. Karpetis, R. S. Barlow, Proceedings of the Combustion Institute 29 (2002) 1147 - 1154

[58] T. W. J. Peeters, P. P. J. Stroomer, J. E. de Vries, D. J. E. M. Roekaerts, C. J. Hoogendoorn, Symposium (International) on Combustion 25 (1994) $1241-1248$.

[59] R. Cabra, T. Myhrvold, J.-Y. Chen, R. W. Dibble, A. N. Karpetis, R. S. Barlow, Proceedings of the Combustion Institute 29 (2002) $1881-1888$

[60] R. Cabra, J.-Y. Chen, R. W. Dibble, A. N. Karpetis, R. S. Barlow, Combustion and Flame 143 (2005) 491-506.

[61] M. J. Dunn, A. R. Masri, R. W. Bilger, Combustion and Flame 151 (2007) $46-60$. 
[62] M. J. Dunn, A. R. Masri, R. W. Bilger, R. S. Barlow, G.-H. 1146 Wang, Proceedings of the Combustion Institute 32 II (2009) 1147 1779-1786.

[63] A. V. Sepman, E. Abtahizadeh, A. Mokhov, J. Van Oijen, H. B. 1149 Levinsky, L. P. H. De Goey, International Journal of Hydrogen 1150 Energy 38 (2013) 13802-13811.

[64] A. V. Sepman, A. V. Mokhov, H. B. Levinsky, Fuel 103 (2013) 1152 $705-710$.

] E. Abtahizadeh, A. V. Sepman, F. Hernández-Pérez, J. van Oi- 1154 jen, A. Mokhov, L. P. H. de Goey, H. B. Levinsky, Combustion 1155 and Flame 160 (2013) 2359-2374.

[66] G. Kuenne, F. Seffrin, F. Fuest, T. Stahler, A. Ketelheun, 1157 D. Geyer, J. Janicka, A. Dreizler, Combustion and Flame 1591158 (2012) 2669-2689.

[67] F. Seffrin, F. Fuest, D. Geyer, A. Dreizler, Combustion and 1160 Flame 157 (2010) $384-396$

[68] D. Geyer, A. Kempf, A. Dreizler, J. Janicka, Proceedings of 1162 the Combustion Institute 30 (2005) 681-688. 1163

[69] M. S. Sweeney, S. Hochgreb, M. J. Dunn, R. S. Barlow, Com- 1164 bustion and Flame 159 (2012) 2912 - 2929.

[70] M. S. Sweeney, S. Hochgreb, M. J. Dunn, R. S. Barlow, Com- 1166 bustion and Flame 159 (2012) 2896 - 2911.

[71] S. Meares, A. R. Masri, Combustion and Flame 161 (2014) 4841168 -495 .

[72] R. S. Barlow, S. Meares, G. Magnotti, H. Cutcher, A. R. Masri, 1170 Combustion and Flame 162 (2015) 3516-3540.

[73] S. Meares, V. N. Prasad, M. Juddoo, K. H. Luo, A. R. Masri, 1172 Proceedings of the Combustion Institute 35 (2015) 3813-3820. 1173

[74] S. Meares, V. Prasad, G. Magnotti, R. Barlow, A. Masri, Pro- 1174 ceedings of the Combustion Institute 35 (2015) 1477-1484. 1175

[75] H. C. Cutcher, R. S. Barlow, G. Magnotti, A. R. Masri, Pro- 1176 ceedings of the Combustion Institute 36 (2017) 1737-1745. 1177

[76] M. Koehler, K. P. Geigle, W. Meier, B. M. Crosland, K. A. 1178 Thomson, G. J. Smallwood, Applied Physics B 104 (2011) 1179 409-425.

[77] D. Gu, Z. W. Sun, B. B. Dally, P. R. Medwell, Z. T. Alwahabi, 1181 G. J. Nathan, Combustion and Flame 179 (2017) 33-50. 1182

[78] B. M. Crosland, K. A. Thomson, M. R. Johnson, Proceedings 1183 of the Combustion Institute 35 (2015) 1851-1859.

[79] M. E. Mueller, Q. N. Chan, N. H. Qamar, B. B. Dally, 1185 H. Pitsch, Z. T. Alwahabi, G. J. Nathan, Combustion and Flame 1186 160 (2013) 1298-1309.

[80] B. Yang, U. Koylü, Combustion and Flame 141 (2005) 55-65, 1188

[81] N. H. Qamar, Z. T. Alwahabi, Q. N. Chan, G. J. Nathan, 1189 D. Roekaerts, K. D. King, Combustion and Flame 156 (2009) 1190 1339-1347.

[82] N. H. Qamar, G. J. Nathan, Z. T. Alwahabi, K. D. King, Pro- 1192 ceedings of the Combustion Institute 30 (2005) 1493-1500. 1193

[83] K. P. Geigle, M. Köhler, W. O'Loughlin, W. Meier, Proceed- 1194 ings of the Combustion Institute 35 (2015) 3373 - 3380.

[84] K. P. Geigle, R. Hadef, W. Meier, J. Eng. Gas Turbines Power 1196 (2014) 021505-1.

[85] K. P. Geigle, J. Zerbs, M. Köhler, M. Stöhr, W. Meier, J. Eng. 1198 Gas Turbines Power 133 (2011) 121503.

[86] M. Gregor, F. Seffrin, F. Fuest, D. Geyer, A. Dreizler, Proceed- 1200 ings of the Combustion Institute 32 (2009) 1739 - 1746.

[87] B. Janus, A. Dreizler, J. Janicka, Proceedings of the Combus- 1202 tion Institute 31 (2007) 3091 - 3098.

[88] C. Schneider, A. Dreizler, J. Janicka, Flow, Turbulence and 1204 Combustion 74 (2005) 103-127.

[89] W. Meier, P. Weigand, X. Duan, R. Giezendanner-Thoben, 1206 Combustion and Flame 150 (2007) 2-26.

[90] W. Meier, X. Duan, P. Weigand, Combustion and Flame 1441208 (2006) $225-236$

[91] P. Weigand, W. Meier, X. Duan, W. Stricker, M. Aigner, Com- 1210 bustion and Flame 144 (2006) 205 - 224.

[92] W. Meier, C. Dem, C. Arndt, Experimental Thermal and Fluid Science 73 (2016) 71 - 78.

[93] U. Stopper, W. Meier, R. Sadanandan, M. Stöhr, M. Aigner, G. Bulat, Combustion and Flame 160 (2013) 2103-2118.

[94] U. Stopper, M. Aigner, H. Ax, W. Meier, R. Sadanandan, M. Stöhr, A. Bonaldo, Experimental Thermal and Fluid Science 34 (2010) 396 - 403

[95] U. Stopper, M. Aigner, W. Meier, R. Sadanandan, M. Stöhr, I. S. Kim, J. Eng. Gas Turbines Power 131 (2008) 021504021504-8.

[96] J. J. Kojima, D. G. Fischer, J.-Y. Chen, Journal of Propulsion and Power 33 (2016) 285-304.

[97] V. G. McDonell, G. S. Samuelsen, ASME. J. Fluids Eng. 117 (1995) 145-153.

[98] J. F. Widmann, C. Presser, Combustion and Flame 129 (2002) $47-86$.

[99] C. Pichard, Y. Michou, C. Chauveau, I. Gökalp, Proceedings of the Combustion Institute 29 (2002) $527-533$.

[100] A. N. Karpetis, A. Gomez, Twenty-Seventh Symposium (International) on Combustion/The Combustion Institute (1998) 2001-2008.

[101] W. O'Loughlin, A. R. Masri, Combustion and Flame 158 (2011) $1577-1590$

[102] A. Kourmatzis, P. X. Pham, A. R. Masri, Combustion and Flame 162 (2015) $978-996$.

[103] J. D. Gounder, A. Kourmatzis, A. R. Masri, Combustion and Flame 159 (2012) 3372 - 3397.

[104] Y.-C. Chen, S. H. Stårner, A. R. Masri, International Journal of Multiphase Flow 32 (2006) $389-412$

[105] C. Chong, S. Hochgreb, Atomization and Sprays 25 (2015) 657-673

[106] C. Chong, S. Hochgreb, Fuel 115 (2014) 551-558.

[107] R. Yuan, J. Kariuki, A. Dowlut, R. Balachandran, E. Mastorakos, Proceedings of the Combustion Institute 35 (2015) 1649-1656.

[108] J. Kariuki, E. Mastorakos, Combustion and Flame 179 (2017) 95-116.

[109] A. Verdier, J. Marrero Santiago, A. Vandel, S. Saengkaew, G. Cabot, G. Grehan, B. Renou, Proceedings of the Combustion Institute 36 (2017) 2595-2602.

[110] F. Shum-Kivan, J. Marrero Santiago, A. Verdier, E. Riber, B. Renou, G. Cabot, B. Cuenot, Proceedings of the Combustion Institute 36 (2017) 2567-2575.

[111] H. Correia Rodrigues, M. Tummers, E. van Veen, D. Roekaerts, Combustion and Flame 162 (2015) 759773.

[112] H. Correia Rodrigues, M. Tummers, E. van Veen, D. Roekaerts, International Journal of Heat and Fluid Flow 51 (2015) 309-323.

[113] U. Meier, J. Heinze, S. Freitag, C. Hassa, in: Proceedings of ASME Turbo Expo 2011: Power for Land, Sea and Air: GT2011, Vancouver, Canada., GT2011-45282.

[114] S. Freitag, U. Meier, J. Heinze, T. Behrendt, C. Hassa, in: Proc. 23rd Annual Conference on Liquid Atomization and Spray Systems, Brno, Czech Republic, 2010

[115] R. S. Barlow, TNF Workshop Abstract, http://www.sandia.gov/TNF/abstract.html, 2018.

[116] A. R. Masri, R. W. Dibble, R. S. Barlow, Progress in Energy and Combustion Science 22 (1996) 307 - 362.

[117] R. S. Barlow, Proceedings of the Combustion Institute 31 I (2007) 49-75.

[118] L. M. Pickett, ECN Workshop Abstract, https://ecn.sandia.gov/ecn-workshop/, 2018.

[119] S. Goldsborough, RCM Workshop Abstract, 
http://www.anl.gov/energy-systems/project/internationalrcm-workshop, 2018. https://www.adelaide.edu.au/cet/isfworkshop/, 2018.

[121] J. H. Frank, S. A. Kaiser, M. B. Long, Proceedings of the Com- 1280 bustion Institute 29 (2002) 2687 - 2694.

[122] M. E. Mueller, V. Raman, Combustion and Flame 187 (2018) 128 $137-146$.

[123] S. Weise, S. Popp, D. Messig, C. Hasse, Flow, Turbulence and 1284 Combustion 100 (2018) 119-146.

[124] J. H. Frank, S. A. Kaiser, J. C. Oefelein, Proceedings of the Combustion Institute 33 (2011) 1373 - 1381. Giusti, E. Mastorakos, C. Hassa, J. Heinze, E. Magens, 1288 M. Zedda, J. Eng. Gas Turbines Power 140 (2018) 061506- 1289 061506-9.

[126] I. Düwel, H.-W. Ge, H. Kronemayer, R. Dibble, E. Gutheil, 129 C. Schulz, J. Wolfrum, Proceedings of the Combustion Insti- 1292 tute 31 (2007) $2247-2255$.

127] B. Zhou, C. Brackmann, Q. Li, Z. Wang, P. Petersson, Z. Li, 1294 M. Aldén, X. song Bai, Combustion and Flame 162 (2015) 1295 $2937-2953$.

[128] H. Wang, E. Hawkes, B. Zhou, J. Chen, Z. Li, M. Aldén, Pro- 1297 ceedings of the Combustion Institute 36 (2017) 2045-2053. ${ }_{1298}$

[129] S.-M. Hwang, R. Kurose, F. Akamatsu, H. Tsuji, H. Makino, 1299 M. Katsuki, JSME International Journal, Series B: Fluids and 1300 Thermal Engineering 49 (2007) 1316-1327.

130] D. Zabrodiec, L. Becker, J. Hees, A. Maßmeyer, M. Haber- 1302 mehl, O. Hatzfeld, A. Dreizler, R. Kneer, Combustion Science 1303 and Technology (2017) 1-25.

[131] I. Boxx, C. Slabaugh, P. Kutne, R. P. Lucht, W. Meier, Pro- 1305 ceedings of the Combustion Institute 35 (2015) 3793-3802. 1306

[132] A. M. Steinberg, I. Boxx, M. Stöhr, C. D. Carter, W. Meier, 1307 Combustion and Flame 157 (2010) 2250-2266.

133] S. Roy, T. Yi, N. Jiang, G. Gunaratne, I. Chterev, B. Emerson, 1309 T. Lieuwen, A. Caswell, J. Gord, Journal of Fluid Mechanics 1310 816 (2017) 554-585.

134] M. Sieber, C. Paschereit, K. Oberleithner, J. Eng. Gas Turbines 1312 Power 139 (2017).

[135] W. L. Oberkampf, T. G. Trucano, Progress in Aerospace Sci- 1314 ences 38 (2002) $209-272$.

[136] B. Fiorina, R. Mercier, G. Kuenne, A. Ketelheun, A. Avdić, 1316 J. Janicka, D. Geyer, A. Dreizler, E. Alenius, C. Duwig, 1317 P. Trisjono, K. Kleinheinz, S. Kang, H. Pitsch, F. Proch, F. C. 1318 Marincola, A. Kempf, Combustion and Flame 162 (2015) 42641319 $-4282$.

[137] W. P. Jones, V. N. Prasad, Combustion and Flame 157 (2010) 1321 $1621-1636$.

[138] A. W. Vreman, B. A. Albrecht, J. A. van Oijen, L. P. H. 1323 de Goey, R. J. M. Bastiaans, Combustion and Flame 1531324 (2008) 394-416.

[139] Q. Tang, J. Xu, S. B. Pope, Proceedings of the Combustion 1326 Institute 28 (2000) $133-139$.

[140] F. Pecquery, V. Moureau, G. Lartigue, L. Vervisch, A. Roux, 1328 Combustion and Flame 161 (2014) 496 - 509.

[141] W. Han, V. Raman, Z. Chen, Combustion and Flame 1711330 (2016) $69-86$.

[142] S. Navarro-Martinez, A. Kronenburg, Proceedings of the Com- 1332 bustion Institute 32 I (2009) 1509-1516.

[143] S. Patwardhan, D. Santanu, K. Lakshmisha, B. Raghunandan, 1334 Proceedings of the Combustion Institute 32 II (2009) 1705- 1335 1712.

[144] R. L. Gordon, A. R. Masri, S. B. Pope, G. M. Goldin, Combus- 1337 tion and Flame 151 (2007) $495-511$.

[145] C. Duwig, M. J. Dunn, Combustion and Flame 160 (2013) 1339 2879-2895.
[146] M. Ihme, Y. C. See, Combustion and Flame 157 (2010) 1850 1862.

[147] F. Proch, P. Domingo, L. Vervisch, A. Kempf, Combustion and Flame 180 (2017) 340-350.

[148] F. C. Marincola, T. Ma, A. M. Kempf, Proceedings of the Combustion Institute 34 (2013) 1307-1315.

[149] G. Kuenne, A. Ketelheun, J. Janicka, Combustion and Flame 158 (2011) 1750 - 1767.

[150] A. Lipatnikov, Progress in Energy and Combustion Science 62 (2017) 1339-1351.

[151] C. Fureby, J. Eng. Gas Turbines Power 134 (2012) 041503 041503-13.

[152] K. Geigle, W. Meier, M. Aigner, C. Willert, M. Jarius, P. Schmitt, B. Schuermans, J. Eng. Gas Turbines Power 129 (2007) 680-687.

[153] E. Fedina, C. Fureby, G. Bulat, W. Meier, Flow, Turbulence and Combustion 99 (2017) 385-409.

[154] S. Jella, P. Gauthier, G. Bourque, J. Bergthorson, G. Bulat, J. Rogerson, S. Sadasivuni, in: Proceedings of the ASME Turbo Expo, Charlotte, North Carolina, USA, June 26-30, 2017, pp. GT2017-65256.

[155] T. Jaravel, E. Riber, B. Cuenot, G. Bulat, Proceedings of the Combustion Institute 36 (2017) 3817 - 3825

[156] G. Bulat, W. P. Jones, A. J. Marquis, Combustion and Flame 161 (2014) $1804-1825$.

[157] M. E. Mueller, H. Pitsch, Combustion and Flame 159 (2012) 2166-2180.

[158] P. Donde, V. Raman, M. Mueller, H. Pitsch, Proceedings of the Combustion Institute 34 (2013) 1183-1192.

[159] F. Sewerin, S. Rigopoulos, Combustion and Flame 189 (2018) 62-76.

[160] O. Park, R. A. Burns, O. R. H. Buxton, N. T. Clemens, Proceedings of the Combustion Institute 36 (2017) 899-907.

[161] M. J. Papageorge, C. Arndt, F. Fuest, W. Meier, J. A. Sutton, Experiments in Fluids 55 (2014).

[162] L. Ma, D. Roekaerts, Combustion and Flame 172 (2016) 2037.

[163] L. Ma, B. Naud, D. Roekaerts, Flow, Turbulence and Combustion 96 (2016) 469-502.

[164] L. Ma, D. Roekaerts, Combustion and Flame 165 (2016) 402423.

[165] S. Gallot-Lavallée, W. P. Jones, A. J. Marquis, Proceedings of the Combustion Institute 36 (2017) 2577 - 2584

[166] M. Mohd Yasin, R. S. Cant, C. T. Chong, S. Hochgreb, Fuel 126 (2014) 44-54.

[167] W. P. Jones, A. J. Marquis, D. Noh, Combustion and Flame 186 (2017) 277 - 298.

[168] M. Sitte, E. Mastorakos, Flow, Turbulence and Combustion 99 (2017) 933-954.

[169] L. Ma, D. Roekaerts, Proceedings of the Combustion Institute 36 (2017) 2603-2613

[170] S. Roy, J. R. Gord, A. K. Patnaik, Progress in Energy and Combustion Science 36 (2010) $280-306$.

[171] A. Bohlin, B. D. Patterson, C. J. Kliewer, The Journal of Chemical Physics 138 (2013).

[172] S. P. Kearney, K. Frederickson, T. W. Grasser, Proceedings of the Combustion Institute 32 I (2009) 871-878.

[173] C. N. Dennis, C. D. Slabaugh, I. G. Boxx, W. Meier, R. P. Lucht, Combustion and Flame 173 (2016) 441 - 453.

[174] A. K. Patnaik, I. Adamovich, J. R. Gord, S. Roy, Plasma Sources Science and Technology 26 (2017) 103001.

[175] A. Bohlin, C. J. Kliewer, The Journal of Physical Chemistry Letters 5 (2014) 1243-1248.

[176] A. Aspden, J. Bell, M. Day, F. Egolfopoulos, Proceedings of the Combustion Institute 36 (2017) 2005 - 2016. 
[177] S. Lapointe, G. Blanquart, Combustion and Flame 167 (2016) $294-307$.

[178] F. Fuest, R. S. Barlow, G. Magnotti, J. A. Sutton, Combustion and Flame 188 (2018) 41-65.

[179] F. Fuest, R. S. Barlow, J.-Y. Chen, A. Dreizler, Combustion and Flame 159 (2012) 2533 - 2562.

[180] M. Rieth, F. Proch, M. Rabaçal, B. Franchetti, F. Cavallo Marincola, A. Kempf, Combustion and Flame 173 (2016) 39-56.

[181] J. Kiefer, P. Ewart, Progress in Energy and Combustion Science 37 (2011) 525-564.

[182] M. E. Mueller, G. Iaccarino, H. Pitsch, Proceedings of the Combustion Institute 34 (2013) 1299-1306.

[183] M. Khalil, G. Lacaze, J. C. Oefelein, H. N. Najm, Proceedings of the Combustion Institute 35 (2015) 1147-1156.

[184] M. T. Reagan, H. N. Najm, R. G. Ghanem, O. M. Knio, Combustion and Flame 132 (2003) 545-555.

[185] C. F. Silva, T. Runte, W. Polifke, L. Magri, J. Eng. Gas Turbines Power 139 (2017).

[186] M. Bauerheim, A. Ndiaye, P. Constantine, S. Moreau, F. Nicoud, Journal of Fluid Mechanics 789 (2016) 534-566.

[187] H. Li, C. Rutland, in: SAE Technical Paper, pp. 2017-010836.

[188] R. Johnson, H. Wu, M. Ihme, Combustion and Flame 183 (2017) 88-101. 